\title{
A Comparative Study of Indoor Pavements Waste Generation During Construction through Simulation Tool
}

\author{
Gómez-Soberón, J.M. ${ }^{1}$; Saldaña-Márquez, H. ${ }^{1}$; Gámez-García, D.C. ${ }^{1}$; \\ Gómez-Soberón, M.C. ${ }^{2} ;$ Arredondo-Rea, S.P. ${ }^{3}$; Corral-Higuera, R. ${ }^{3}$ \\ Universitat Politècnica de Catalunya $(U P C)^{1}$; Universidad Autónoma Metropolitana \\ $(U A M)^{2}$; Universidad Autónoma de Sinaloa $(U A S)^{3}$
}

\begin{abstract}
The construction sector affects the environment through $\mathrm{CO}_{2}$ emissions generated by the use of massive quantities of materials, energy, and wastes during the construction and demolition processes. Moreover, current technology offers a wide variety of materials, products, and systems that could be used for a similar solution; however, the decision to select one or other element lies with the price and then by regulatory requirements and availability (ignoring the issue of sustainability). In a building, the pavements are one of the elements with major representativeness and with more possibilities of alternative variables in their materials; accordingly, this research exposes three different types of pavements with similar prices, comparable functions, and normative compliance, but providing a new sustainable perspective: The construction and demolition waste $(C \& D W)$ analysis. The results show the differences between the waste generated from each type of pavement, stressing that the application of sustainable management criteria can be significant for sustainable buildings construction. This research shows a new criterion applicable to the construction sector that could improve the selection (with equal requirements) of one type of pavement into a more environmentally friendly pavement; allowing the achievement of profits for builders.
\end{abstract}

\section{Introduction}

Currently, one of the biggest challenges facing the planet is caused by waste generation and their accumulation in landfills, being the C\&DW the most representative [1]. In a building, different construction phases arise including the execution of pavements; which are considered as the elements with the larger horizontal surface, being one of the main causes of C\&DW [2].

In this research, the waste generated (considering construction and eventual demolition) by three types of usual interior pavements in Spain are analysed, compared and quantified through simulation. The main purpose of this research is to establish and identify which type of pavement generates more wastes and what relationship maintained between them in order to find an effective solution during the materials selection process for the execution construction of new and existing buildings three types of pavements were applied in the same case study (multi-family housing located in Barcelona, with a pavement total area of $2,341.00 \mathrm{~m}^{2}$ ); The constructive application was equivalent and with comparable feasibility of use; the selected pavements were: Indoor terrazzo tile (P1), ceramic rustic tile (P2) and Spanish granite tile (P3); The Net Waste Tools software (NWT) was used (with the data of the selected pavements) as a simulation tool, this allowed us to obtain reports for each type of pavement, finally, these reports were standardized to make comparisons.

Results indicate that, although the analysed indoor pavements could be used (solving the technical requirements, regulations, construction difficulty and similar prices), their estimated waste generation is not the same for all of them, enabling us to highlight that this type of analysis can perceive differences which have passed unnoticed by the construction sector so far, with an additional contribution that could be seen as a new approach that promotes sustainability, environmental care and financial savings for the construction sector.

\section{Body of knowledge}

It is expected that the world population growth will double before the middle of this century, and as a binding cause of this, it is also predicted that this trend will be further accentuated in urban and bordering areas. Taking into account the increasing limitations of building areas in large cities, the building sector seems to be obliged to define new solutions to this problem [3]. Among them, the validation of constructive systems to achieve sustainable housing could contribute in this regard.

Of all the different elements in a building construction, the interior pavements have a high proportion and representation in a work -by a number of materials they use and for horizontal surface of their service-, and nevertheless they have not yet been linked to optimization criteria for comparable sustainable ratification -notwithstanding the existing of a wide variety of similar systems and constructive solutions-; although it has been accepted that the use of more complex systems (diversity of materials and in wet-laying construction) may be less sustainable than those using less variety of materials (with an implementation in-situ simpler). In Spain, 
during the period from 1990 to 2007, the construction of housing, urban development, and infrastructures, reported an increase of $40 \%$, which led to an increase in the consumption of materials in general above $141 \%$ in that period [4] (including those required by pavements).

Sustainable development, and therefore the sustainable construction as well, have become a growing concern throughout the planet. This concern can be identified through of the comprehension of the contamination effects over the environment, by the forecasts of short-term natural resource depletion, by the increase in waste generation, and by the social problems that these can entail.

Construction is one of the productive sectors that consumes large amounts of natural resources and represents a significant percentage of greenhouse gas emissions on the planet. Just in the US, the construction sector accounts for $38.9 \%$ of primary energy consumption, $38 \%$ of all $\mathrm{CO}_{2}$ emissions, and $30 \%$ of waste production [5]. Similarly, in the European Union (EU), building construction consumes $40 \%$ of primary energy, $40 \%$ of all materials and generates $40 \%$ of wastes [6].

In terms of demolition waste from construction, the EU reports nearly 450 million tons per year, of which only $25 \%$ of them are retrievable [7], while in Spain, it is estimated that of the total waste generated throughout the country, $70 \%$ correspond directly to waste from activities related with C\&DW [6]. Also, $\mathrm{CO}_{2}$ emissions from the residential, commercial and institutional sector show increases of $65 \%$ compared to 1990 , with the domestic and building sectors consuming $20 \%$ of total energy, producing at the same time, $25 \%$ of the total $\mathrm{CO}_{2}$ emissions [8].

With respect to the foregoing, it is important to emphasise that building indoor pavements represent a contrasted environmental impact, a significant consumption of raw materials, an important use of energy for its construction and use, and an application of elements for its construction composition, in some cases they become unnecessary.

Buildings for residential use, and in particular indoor pavements, should be evaluated under comparable criteria to corroborate its unjustified overpower in the generation of waste and the use of recycled materials for their elaboration with the most suitable alternative building systems.

According to data published for Spain [9], about 40 million tonnes of waste are produced each year in the construction sector, accounting for $32 \%$ of the total volume of the country. Therefore, if the previous hypothesis is verified (regarding the uncertainty that presents the sustainability in the generation of the C\&DW of different pavements for the dwellings), then it could be argued or established, and thus contribute to save on raw materials, to preserving natural resources, to preserve environmental quality, to ensure public health, using recycled materials [10], to the waste reduction and to the sustainable development in general.

\section{C\&DW simulation and comparison}

In Spain, the different areas involved in the construction process are obliged to include a waste management study document within the project execution [11], this document includes an estimate of the C\&DW to be generated (in tonnes and $\mathrm{m}^{3}$ ), using reliable simulation methods [12].

Several researchers have developed methodologies to quantify $\mathrm{C} \& \mathrm{DW}$ in response to the regulation of establishing ranges and parameters that describe them. For example, in Holland [10] the classification is made by weight, and make distinction between elements such as: remains of piles, ceramic bricks, concrete, blocks, tiles, mortars, aggregates, etc. (result of a study of 184 houses that developed in 5 projects), the conclusion reached was that from all the construction materials supplied at the construction site, between 1 and $10 \%$ of them, will end up becoming waste.

In Canada [13], it is used as reference, the programming of works to simulate through models the generation of residues of some materials: metal, wood, plasterboard, concrete, etc.

In the United States, the estimation principle is applied, based on multiplying the construction, rehabilitation or demolition area by a generation coefficient of C\&DW, thus obtaining the amount of C\&DW in a geographic area of study; and using this system to establish the need for provide installation of recycling facilities in each geographical area [14], or for C\&DW generation studies by sectors (residential and non-residential construction, residential and non-residential rehabilitation and residential and non-residential demolition) [15].

Similarly, there are other experiences in Florida [16], Massachusetts [17]; as well as in other countries such as Thailand, [18].

Finally, through the modelling of stock of materials and their flows (dynamic modelling), the estimation of C\&DW in buildings in Taiwan, the Netherlands and Norway has also been studied.

Although there are several worldwide principles [12], the methodology is based on:

1) Description and analysis of its constructive characteristics.

2) Analysis of measurements and budget (standardisation, structuring, organising and coding the information to be used).

3) Identification and analysis of the measurements from which the table of decomposed unit prices is made and the construction system for each unit of work to be analysed are identified. 
4) Analysis and measurement on the site of waste generated during the execution of each construction element (including packaging, type, volume, weight, dimensions, material, etc.).

5) Application of the waste form for each waste.

6) Estimation of types and quantities of waste per unit of work (theoretical model of waste quantification).

7) Adaptation of the theoretical model to the results obtained.

In this sense, there are several software tools that allow to estimate the types and quantities of C\&DW; among them, the NTW software has previously been used as a tool to define a sustainable criterion for the minimization of environmental effects, allowing the selection of different alternative types materials (concrete, steel, and wood), as a comparison of alternative construction processes (between multifamily housing or single-family homes), or of similar building systems (between bidirectional or unidirectional forging) [1].

Therefore, sustainability in construction could provide new solutions to the current paradigms of our society; among them, the establishment of new environmental criteria (minimum generation of C\&DW) in the choice of construction systems (indoor pavements) that match criteria of use or regulation, but at the same time, the selected systems can become sustainable.

\section{Methodology}

The present study makes a comparison of three alternatives of indoor pavements, chosen according to the characteristics required for their application in dwellings spaces and the items of the price generator of the CYPE S.A.V. 2015i software [19]; as well as a comparative analysis of the three selected alternatives based on the results of the NWT software, in which the unit of reference taken was the square metres of surface of each one of the spaces of the case proposed for his study.

\subsection{Description of the case study}

The case study $\left(41^{\circ} 24^{\prime} 17.6^{\prime \prime} \mathrm{N} 2^{\circ} 10^{\prime} 12.8^{\prime \prime} \mathrm{E}\right)$ is located on a lot of $705.60 \mathrm{~m}^{2}$ of which $346 \mathrm{~m}^{2}$ correspond to the gross floor area (see Figure 1).

The building has 34 apartments and one commercial unit on the ground level. It consists of a ground floor, a mezzanine floor, six similar upper floors (four apartments by level), an attic (two apartments) and an upper attic (two apartments).
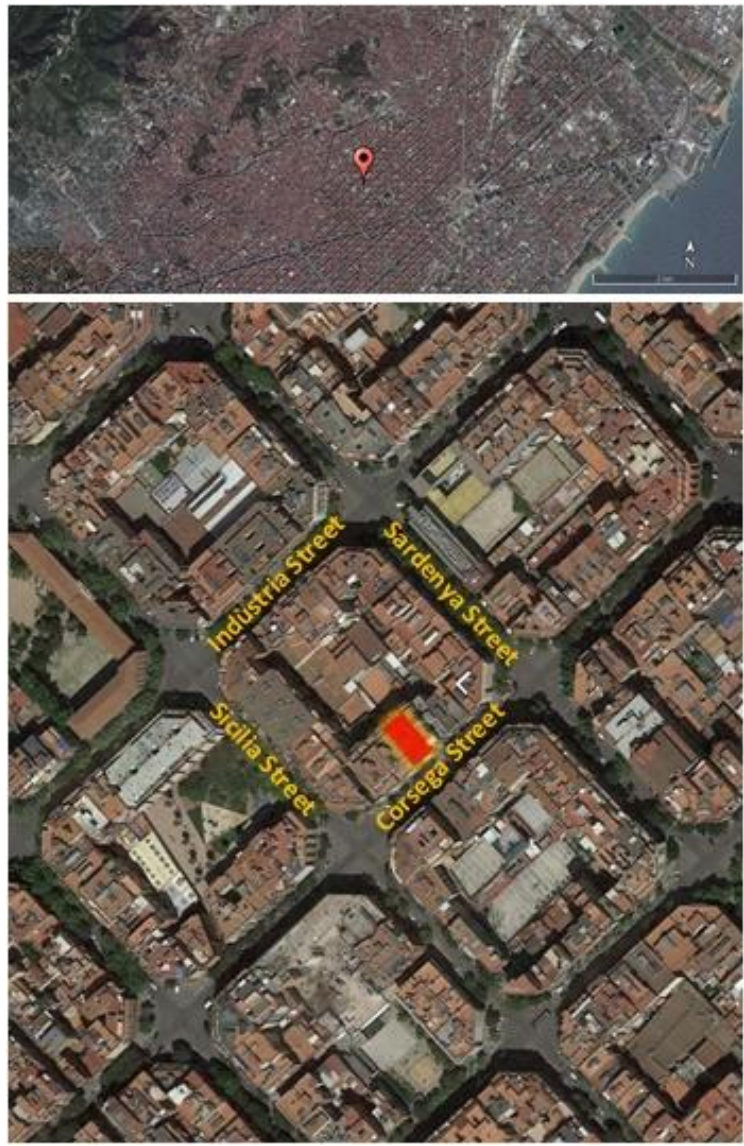

Figure 1. Location of the case study

Table 1 shows the total surfaces of each of the floor and the final average to be taken into account to perform the calculations.

Table 1. Total surfaces

\begin{tabular}{|l|c|}
\hline \multicolumn{2}{|c|}{ Total square metres per floor* } \\
\hline Ground floor & 80.00 \\
\hline Mezzanine floor & 242.72 \\
\hline Floors 1 to 6 & 1656.36 \\
\hline Attic & 230.18 \\
\hline Upper attic & 131.72 \\
\hline Total & $\mathbf{2 3 4 0 . 9 8}$ \\
\hline
\end{tabular}

The typical apartment presents the following distribution of spaces: Living/dining room, kitchen, four bedrooms, bathroom and separate $\mathrm{WC}$ and sink (see Figure 2). 


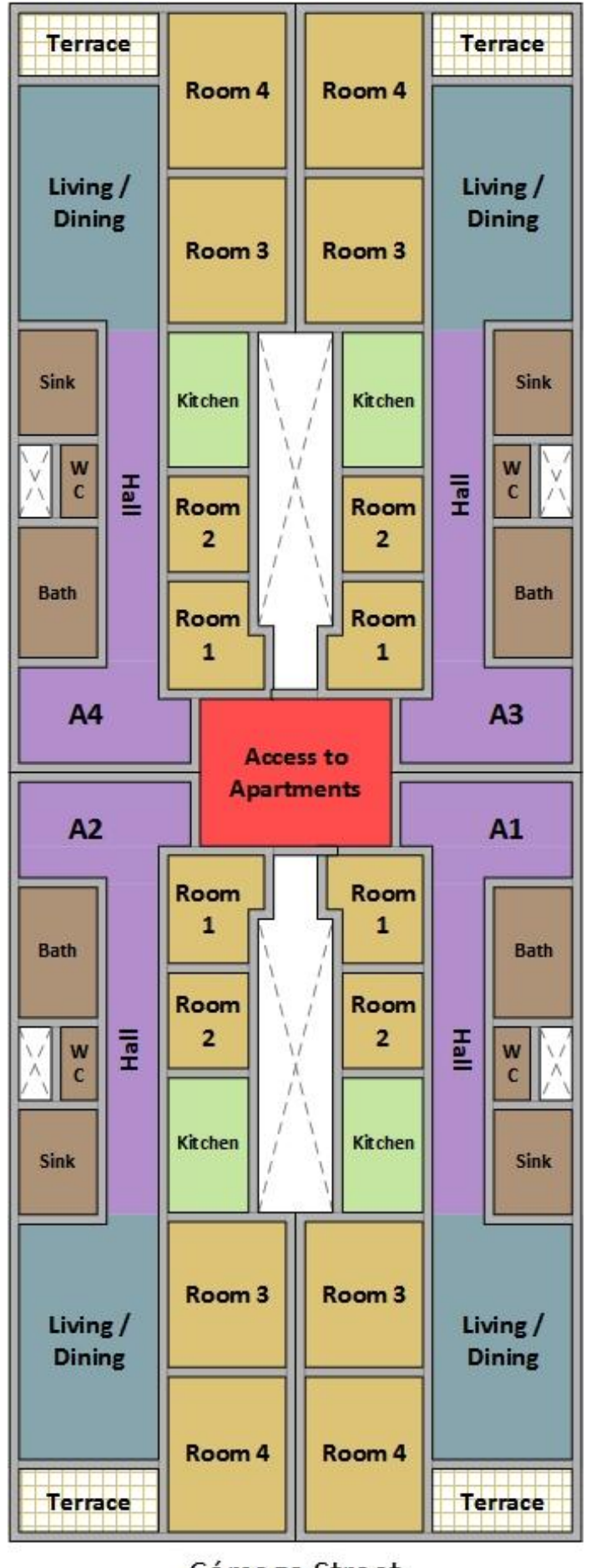

Córsega Street

Figure 2. Floor plan: Apartments distribution

\subsection{Selected materials}

The three alternatives selected for the study were: prefabricated terrazzo, as a regenerated stone $(\mathrm{P} 1)$; rustic stoneware, as a ceramic material (P2); and finally granite as a polished stone material (P3). The pavements studied correspond to the total communal areas and housing, and the three comply with the requirements of the Spanish regulation (SU1:
Security against the risk of falls, and DB-SUA: utilisation and accessibility security; both specifications are included in the CTE -Technical Code of the Edification-). Figure 3 shows the geometry and configuration per square metre of the three selected pavements.

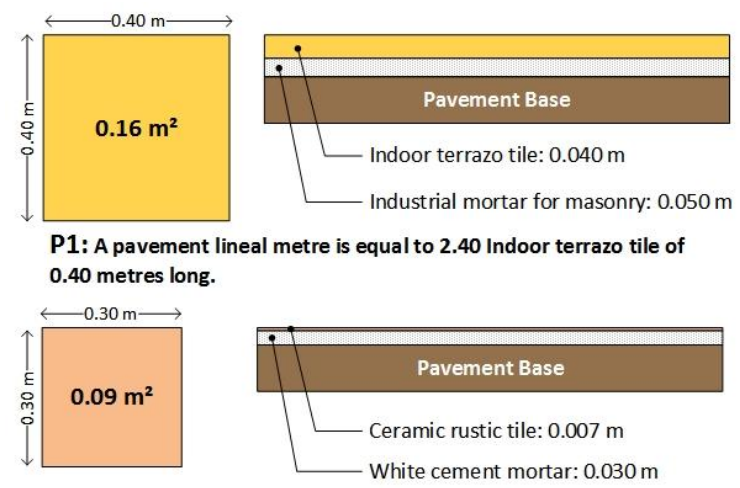

P2: A pavement lineal metre is equal to 3.31 Ceramic rustic tile of 0.30 metres long.

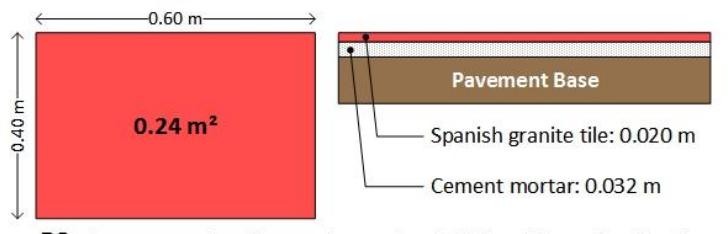

P3: A pavement lineal metre is equal to 1.66 Spanish granite tile of 0.60 metres long.

Figure 3. Geometry and configuration of pavements

4.2.1. Prefabricated terrazzo. According to [20], the terrazzo tile is a prefabricated element of compacted concrete with uniform shape and thickness, it meets the geometrical requirements specified therein and may be single-layer or twolayer. Among the many advantages of this type of pavement during construction and its useful life are: great resistance and durability against impacts and wear that can produce pedestrian traffic, furniture or vehicles for indoor transportation; allows its placement without finishing all the phases of the work; provides surface finishes smooth and rough; the factory process of this tile allows to view the aggregates and the colour of mortar; possibility of finishing in situ (thus eliminate manipulation or placement defects); finally, allows giving a continuous appearance and maximizing aesthetic, environmental, nobility and compactness conditions [21].

4.2.2. Rustic stoneware. Is a pavement of high performance and aesthetics, its characteristics such as compactness, vitrified, minimal porosity and thermal insulation makes it suitable for its use in indoor areas. Among its variety is the rustic stoneware, an extruded ceramic tile, particularly distinguished for its decorative features such as unevenness in colour, surface and edges [22]. 
According to [22] the most predominant tiles are those of square shapes ( $11 \times 11$ centimetres $)$ and the rectangular (11 x 37 centimetres), varying thicknesses according to types and measurements.

4.2.3. Granite. Within the classification of pavements, granite is a polished stone (of the most used rocks in the construction), it is composed of feldspar, quartz and mica, they have a crystalline structure, it is considered a discontinuous pavement, compact, difficult to work and unalterable in outdoor environment; it has a good environmental performance and adequate resistance to compression and abrasion. The pieces of this type of stone are produced in the form of slabs, tiles and plates; the largest size used are the square tiles of $20 \times 20$ to 50 $\mathrm{x} 50$ centimetres, arranged in a grid or diagonal space. The thickness of these is usually two centimetres and in some cases fifteen millimetres, its finishing surface is worked by means of a polishing with portable machines of the horizontal disc [21].

\subsection{Prices generator}

The construction costs adjusted to the market and to the different characteristics and typologies of a building located in Spain were obtained from the price generator for the construction CYPE S.A.V. [19]; which facilitates the elaboration of useful documents for the different phases of the life cycle building taking into account concrete characteristics of each building and generating specific prices for the project to be budgeted. The prices generator of the CYPE presents a variety of options for each of the characteristics that define a material, therefore, the appropriate selection of the criteria and the use the material will have, they will determine the final description and the price of each item. Table II shows, for each pavement, the specific quantities and prices of inputs materials that were used in the simulation.

\subsection{Simulation tool}

The NWT is an open-access online software tool, developed by the Waste and Resources Action Program [23] and aimed for customers, design teams and contractors, its functions are:

1) Combine the analysis of recycled material content and analysis of waste.

2) Calculate the possible residues to generate in each one project of new construction, rehabilitation or infrastructure, to improve the content of recycling and to quantify the waste of the project in general.

3) Calculate the costs and quantities of waste.

4) And, identify the most appropriate strategies to improve performance.
These functions have been verified to be adequate in helping to:

1) Generate the waste forecasts needed for a waste management plan.

2) Reduce construction costs by wasting less material.

3) Define actions for a waste management plan.

4) Optimise the choice of containers.

5) Reuse the largest amount of materials in the construction and opt for products with higher recycled content.

6) And evaluate performance to reduce waste to landfill, among other.

In general, the NWT seeks to save costs on material and disposal from design principles [23-24]. On the other hand, the NWT has been designed so that through simple web pages, basic information of the project and the materials could be used to obtain the analysis of the waste and recycled materials management. Once the information of a given material is entered, the tool estimates the levels of waste based on any of the values of the wasted material component. At the end of the process, when the results are obtained, the user can identify specific actions to reduce the levels of waste generated and classify the information for any of the values of the discarded materials principles [24].

\section{Results and discussion}

Figure 4 shows the results of NWT tool, partially expressed the percentages of each pavement studied in tonnes and grouped according to the European Waste Catalogue (CER).

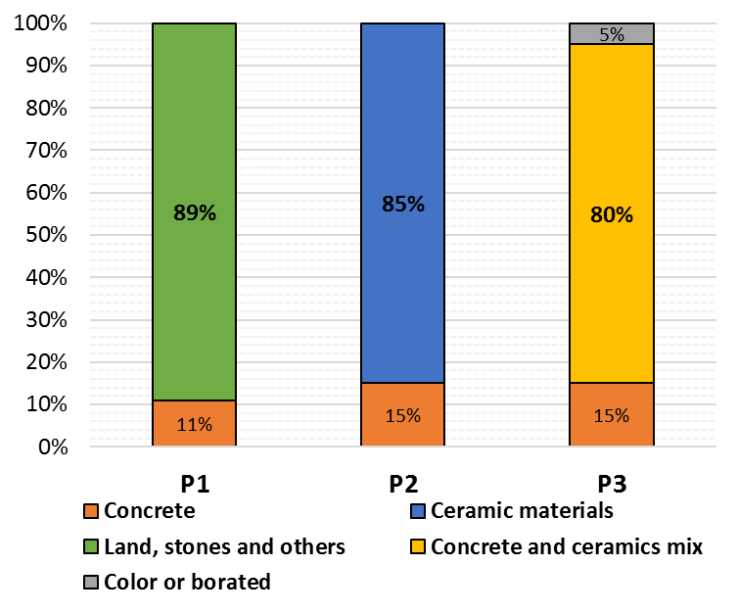

Figure 4 . Waste generated by pavement

The types of waste generated from the simulation were: tile materials and concrete. The tile materials generate the largest amount of waste, because of the "grip" and the joints (the concrete), since this material contains the highest percentage of pavements. 
Table 2. Description of pavements

\begin{tabular}{|c|c|c|c|c|}
\hline \multicolumn{5}{|c|}{ P1 } \\
\hline Unit & \multicolumn{4}{|l|}{ Description } \\
\hline $\mathrm{m}^{2}$ & \multicolumn{4}{|c|}{$\begin{array}{l}\text { P1 (Terrazzo flooring). Tile flooring terrazzo medium grain ( } 6 \text { to } 27 \mathrm{~mm} \text { ), classified normal use for indoor, } 40 \times 40 \mathrm{~cm} \text {, beige, } \\
\text { positioned on a bed of cement mortar, industrial, } \mathrm{M}-5 \text {, and grouted with white cement grout BL-V } 22.5 \text { coloured with the } \\
\text { same tonality of the tiles. }\end{array}$} \\
\hline Unit & Broken down & Performance & Unit price & Item price \\
\hline $\mathrm{m}^{3}$ & Water & 0.011 & 1.50 & 0.02 \\
\hline $\mathrm{t}$ & $\begin{array}{l}\text { Industrial mortar for masonry, of cement, sand, class M-5 (compressive strength } 5 \\
\mathrm{~N} / \mathrm{mm}^{2} \text { ), supplied in sacks, according to UNE-EN 998-2. }\end{array}$ & 0.060 & 32.25 & 1.94 \\
\hline $\mathrm{m}^{2}$ & $\begin{array}{l}\text { Indoor terrazzo tile, normal use, medium grain ( } 6 \text { to } 27 \mathrm{~mm}) \text {, nominal } 40 \times 40 \mathrm{~cm} \text {, beige } \\
\text { colour, with the first polishing in the factory, for polishing and buffing final in work, } \\
\text { according to UNE-EN 13748-1. }\end{array}$ & 1.050 & 10.25 & 10.76 \\
\hline $\mathrm{kg}$ & White cement BL-22.5 X, for paving, in sacks, according to UNE 80305. & 1.000 & 0.14 & 0.14 \\
\hline $\mathrm{kg}$ & Grout coloured with the same tonality of the tiles, for terrazzo paving. & 0.500 & 1.15 & 0.58 \\
\hline $\mathrm{h}$ & Official 1st. & 0.192 & 17.24 & 3.31 \\
\hline $\mathrm{h}$ & Assistant. & 0.354 & 16.13 & 5.71 \\
\hline$\%$ & Auxiliary resources & 2.000 & 22.46 & 0.45 \\
\hline$\%$ & Indirect costs & 3.000 & 22.91 & 0.69 \\
\hline \multicolumn{3}{|c|}{ Ten-year cost of maintenance: $2,12 €$ in the first 10 years. } & Total: & 23.60 \\
\hline \multicolumn{5}{|c|}{$\mathbf{P 2}$} \\
\hline Unit & \multicolumn{4}{|l|}{ Description } \\
\hline $\mathrm{m}^{2}$ & \multicolumn{4}{|c|}{$\begin{array}{l}\text { P2 (Ceramic tiles flooring with cement as a bonding material). Ceramic tile flooring rustic tile, } 3 / 2 / \mathrm{H} /-, 30 \times 30 \mathrm{~cm}, 15.13 \\
€ / \mathrm{m}^{2} \text {, bonded with white cement mortar } B L-I I / A-L 42.5 \mathrm{R} \mathrm{M}-5 \text { of } 3 \mathrm{~cm} \text { thick and grouted with cementitious mortar joints with } \\
\text { high resistance to abrasion and reduced water absorption, CG2, for minimum joint (between } 1.5 \text { and } 3 \mathrm{~mm} \text { ), with the same } \\
\text { tonality of the pieces. }\end{array}$} \\
\hline Unit & Broken down & Performance & Unit price & Item price \\
\hline $\mathrm{m}^{3}$ & $\begin{array}{l}\text { White cement mortar BL-II/A-L } 42.5 \mathrm{R} \text {, type } \mathrm{M}-5 \text {, made on site with } 250 \mathrm{~kg} / \mathrm{m}^{3} \text { cement } \\
\text { and a volume ratio } 1 / 6 \text {. }\end{array}$ & 0.030 & 88.34 & 2.65 \\
\hline $\mathrm{m}^{2}$ & Ceramic tile rustic tile 3/2/H/-, 30×30 cm, $15.13 € / \mathrm{m}^{2}$, according to UNE-EN 14411. & 1.050 & 15.13 & 15.89 \\
\hline $\mathrm{Kg}$ & $\begin{array}{l}\text { Cementitious mortar joints with high abrasion resistance and reduced water absorption, } \\
\text { CG2, for the minimum joint between } 1.5 \text { and } 3 \mathrm{~mm} \text {, according to UNE-EN } 13888 \text {. }\end{array}$ & 0.100 & 0.99 & 0.10 \\
\hline $\mathrm{H}$ & Official 1st. & 0.273 & 17.24 & 4.71 \\
\hline $\mathrm{h}$ & Assistant. & 0.137 & 16.13 & 2.21 \\
\hline$\%$ & Auxiliary resources & 2.000 & 25.56 & 0.51 \\
\hline$\%$ & Indirect costs & 3.000 & 26.07 & 0.78 \\
\hline \multicolumn{3}{|c|}{ Ten-year cost of maintenance: $4.56 €$ in the first 10 years. } & Total: & 26.85 \\
\hline \multicolumn{5}{|c|}{ P 3} \\
\hline Unit & \multicolumn{4}{|l|}{ Description } \\
\hline $\mathrm{m}^{2}$ & \multicolumn{4}{|c|}{$\begin{array}{l}\text { P3 (Natural stone flooring with cement mortar as a bonding material). Granite tile flooring Grey Villa, interior, } 60 \times 40 \times 2 \mathrm{~cm} \text {, } \\
\text { flamed finish, received with cement mortar } \mathrm{M}-5 \text { and bonded with cementitious mortar joints, CG1, for minimum joint } \\
\text { (between } 1.5 \text { and } 3 \mathrm{~mm} \text { ), with the same tonality of the pieces. }\end{array}$} \\
\hline Unit & Broken down & Performance & Unit price & Item price \\
\hline $\mathrm{m}^{3}$ & $\begin{array}{l}\text { Cement mortar CEM II/B-P } 32.5 \mathrm{~N} \text {-type } \mathrm{M}-5 \text {, made on site with } 250 \mathrm{~kg} / \mathrm{m}^{3} \text { cement and a } \\
\text { volume ratio } 1 / 6 \text {. }\end{array}$ & 0.032 & 115.30 & 3.69 \\
\hline $\mathrm{m}^{2}$ & Spanish granite tile, Grey Villa, 60×40×2 cm, flamed finish, according to UNE-EN 12058. & 1.050 & 30.05 & 31.55 \\
\hline $\mathrm{kg}$ & $\begin{array}{l}\text { Cementitious grout, CG1, for the minimum joint between } 1.5 \text { and } 3 \mathrm{~mm} \text {, according to } \\
\text { UNE-EN } 13888 \text {. }\end{array}$ & 0.150 & 0.70 & 0.11 \\
\hline $\mathrm{h}$ & Official 1st. & 0.314 & 17.24 & 5.41 \\
\hline $\mathrm{h}$ & Assistant. & 0.314 & 16.13 & 5.06 \\
\hline$\%$ & Auxiliary resources & 2.000 & 45.82 & 0.92 \\
\hline$\%$ & Indirect costs & 3.000 & 46.74 & 1.40 \\
\hline & Ten-year cost of maintenance: $4.33 €$ in the first 10 years. & & Total: & 48.14 \\
\hline
\end{tabular}

The common material, in the three studied systems, was concrete; reaching percentages, with respect to the total of the remaining materials of $15 \%$ for $\mathrm{P} 2$ and $\mathrm{P} 3$, and $11 \%$ for $\mathrm{P} 1$.

For P1 and P2, only two materials are expected to be generated: concrete in both cases; ceramic materials, and land, stones and others, respectively.

Finally, for P3, it is expected to generate concrete, concrete and ceramic mix materials and borated. In the three cases, the material that is always present is the concrete (with average values of 14\%); however, the most representatives (average of 85\%) are the ceramic materials or mixtures of them with others, reflecting the difficulty of a single feasible segregation ( $\mathrm{P} 2$ is an exception that produces not combined ceramic).

Thinking about possible implications during the construction of the study cases through a standard or conventional waste management (without sustainable criteria) and a desirable or ideal waste management (with sustainable criteria), an establishing criteria of normalization of the data to the variables: According to the size of the tile (a), the construction cost (b), and a number of tiles per square metre (c), were considered. The Figure 5 shows the comparative study of the selected pavements (per tonnes and 
cubic metres respectively, and per value of waste generated).

In the case of tonnes and cubic metres, the waste generated by the $\mathrm{P} 3$ are the most in volume and in weight producers (Concrete and ceramic materials mix), also in the three cases, the standard management produce significantly more waste when compared with the desirable management. Furthermore, the unit of cubic metres proves to be the most representative form of measurement. From these three graphs, the standardisation criteria that best allow to discern the behaviour are the size of the tiles (highest numerical scale in the vertical axis).

In terms of waste generated, the waste which presents the highest value varies according to the normalization criteria: for "a)" is the P2 (ceramic materials), for "b)" and "c)" is the P1 (land, stones and others); considering the number of tiles per square metre like the most sensitive criterion of normalization for the three cases. Moreover, in all cases, the standard management always generates more wastes than the desirable management.

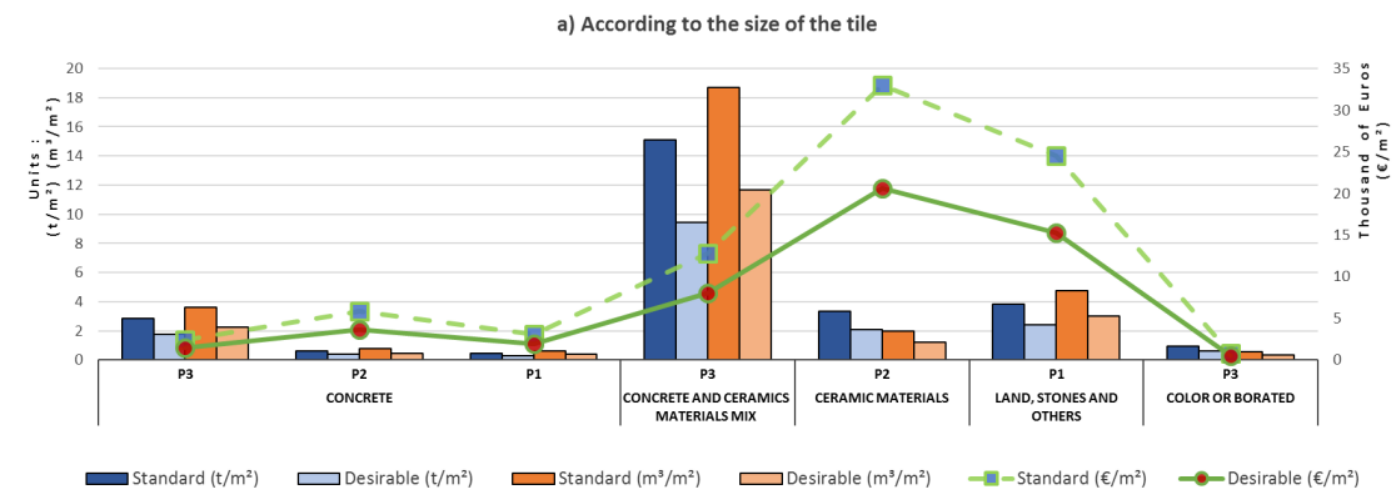

b) According to the construction cost
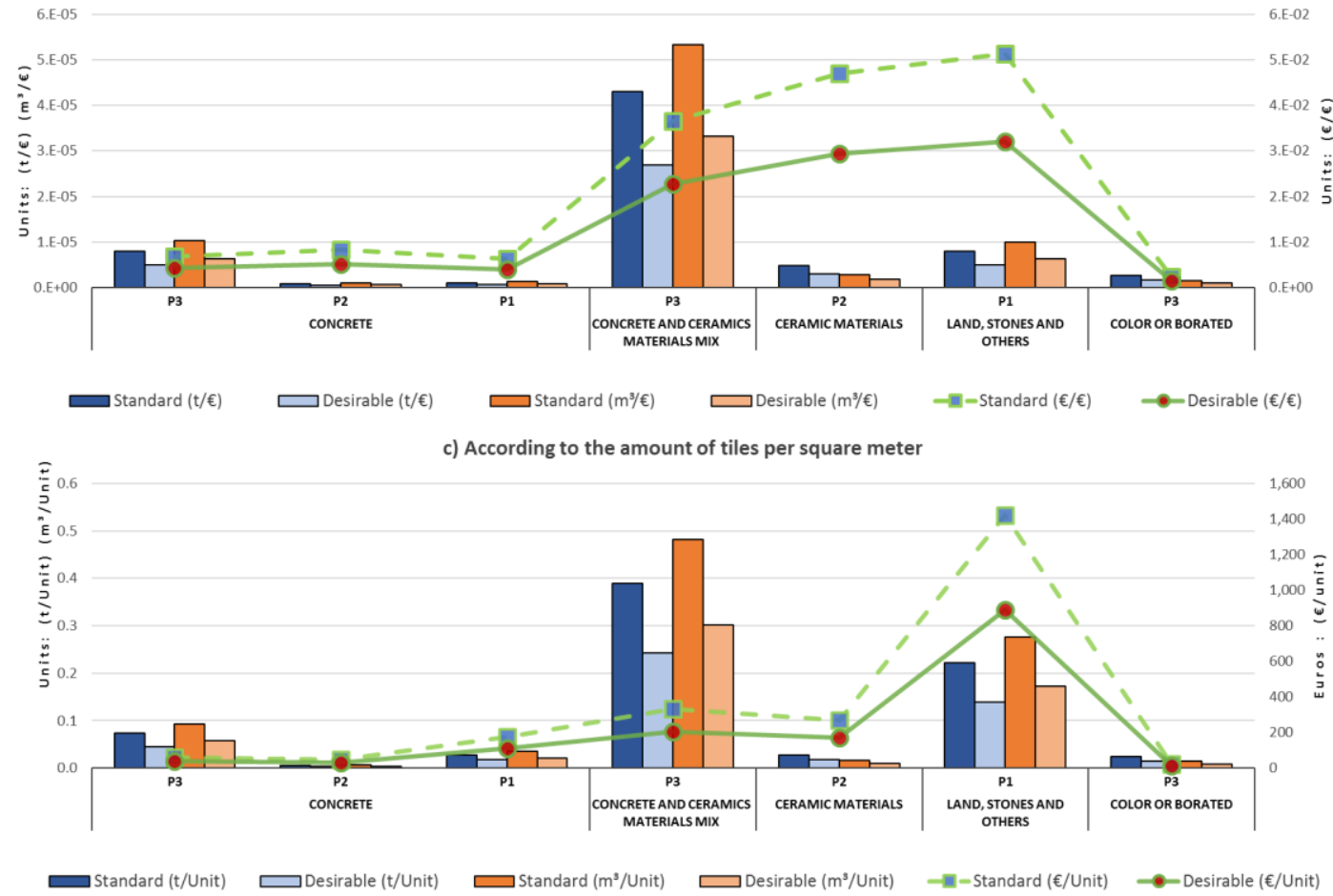

Figure 5. Comparison of the selected pavements according to a desirable or standard management

The most expensive internal flooring solution to deal with waste was granite (P3), followed by rustic stoneware tiles (P2) and finally the terrazzo tiles (P1). The cost difference between P1 and P2 is not significant, but $\mathrm{P} 3$ exceeds more than twice the cost of material and the cost of construction of P1 (attributed to the high cost of this material)
The total cost of recycling internal pavement materials has always proved to be greater in "standard" than in "desirable" management (since minimization techniques are not used in the first). For the cost of "desirable" management resulted in this study with "negative" values, understood as the value of the recycled and reused materials (added to 
the work) greater than the value of the eliminated waste; the total cost of recycling is zero (obtaining a profit).

Project P1 is the one with the lowest negative value, that is, the project that could have the lowest cost of recycling due to its high recycled content, compared to the others; therefore, there is greater potential for recovery of materials.

The highest yield in waste reduction occurs in the P3 project with a $26.61 \%$ reduction in tonnes of waste. And a $38.53 \%$ reduction in the cost of containers, despite the fact that the increase in the value of recovered materials was only $10 \%$.

Finally, the reduction of waste types when applying the desired management over a standard is $37.50 \%$ in all cases by weight, volume and cost; So it can be said that applying waste minimization techniques, and establishing an adequate management of them, will generate economic and environmental benefits; since the tons of material destined for landfills will occupy lower volumes and at lower cost.

From the homogenization parameters used in the normalization of data, the thickness and size of the tiles were the ones that best describe and allow to establish the correlations between the different variables studied (greater distance of the data in the correlation graphs); therefore, this parameter should be selected as the most suitable for future choices, since it allows distinguishing the different more "sustainable" internal pavements.

\section{Conclusions}

In building construction, the waste generated (in particular the C\&DW) represents an important opportunity to obtain recycled material such as aggregates for alternative use or applications within the same work where they are produced (reuse and recycling of materials); Also, this could (incorrect waste management) produce a great negative impact on the environment due to its accumulation in landfills. Determining the amount and types of waste generated by different interior pavements can lead to a sustainable improvement in the construction industry, reducing waste and prevent subsequent landfill site.

The analysis of the different component materials of the studied pavements, proves that establishing waste minimization techniques and an adequate management of these residues, brings economic benefits for the project and the environment, since it avoids the unnecessary use of materials in the project and generates less waste in the process of its execution. This was evident in the differences obtained from both prices and C\&DW volumes in a "desirable" management to a "standard" (obtained in the simulation of the C\&DW with the use of NWT).
With respect to the yield obtained in the three systems studied, it is possible to say that a "standard" management with respect to a "desirable" indicates that applying waste minimization techniques will improve and minimise contamination and costs of elimination.

Analysing the constructive studied systems, it was observed that P1 is the one that generates the greatest quantity of residues (greater thickness, and therefore greater weight and volume); while P2 (of the lower thickness of tile and mortar) reports the least amount of residues in weight and volume. This indicates that the volume and density of the materials (tiles and concrete) influence the generation of waste material, and therefore the system of interior pavements with greater volume and density will be the more likely in generating residues (weight and volume).

Finally, despite the fact that P3 is a natural stone and Spanish legislation recommends this pavement to be considered for use in any space; in this investigation, this is the one that has the highest cost of the construction and lower recovery percentage of materials (caused by its manufacturing process); but on the other hand, it is the one that obtains a greater yield when applying a "wanted" management of its residues (in weight and the volume).

\section{References}

[1] Gómez Soberón, J. M. V., Corral Higuera, R., Arredondo Rea, S. P., Soberón, G., Consolació, M., \& Guerrero Díaz, I. E. A. (2011). Evaluación de residuos como criterio comparativo de procesos constructivos. In II European Conference on Energy Efficiency and Sustainability in Arquitecture and Planning, 348-348. Universidad del Pais Vasco.

[2] de Santos Marián, D., Delgado, B. M., \& Martínez, A. G. (2010). Gestión de residuos en las obras de construcción y demolición. Tornapunta.

[3] Agamuthu, P. (2008). Challenges in sustainable management of construction and demolition waste. Waste Management \& Research, 26(6), 491-492.

[4] Instituto Nacional de Estadística (National Statistics Institute) (2011); http://www.ine.es/ (1 May 2011).

[5] U.S. Green Building Council (USGBC), (2011); http://www.usgbc.org/ (1 May 2011).

[6] Hendriks, C. F., \& Pietersen, H. S. (2000). Report 22: SUSTAINABLE raw materials: construction and demolition waste-state-of-the-art report of RILEM technical committee 165-SRM(Vol. 22). RILEM publications.

[7] European Environmental Agency (EEA), (2002). Review of selected waste streams. Copenhagen, Denmark. 
[8] Green Building Council españa (GBCe), (2011); http://www.spaingbc.org/. (1 May 2011).

[9] PMGRM Commission of Revision, (2006). $2^{a}$ revisió 2004-2006 Programa Metropolità de Gestiò de Residus Municipals. Barcelona, Spain.

[10] Bossink, B. A. G., \& Brouwers, H. J. H. (1996). Construction waste: quantification and source evaluation. Journal of construction engineering and management, 122(1), 55-60.

[11] Ministerio de Presidencia, Gobierno de España, Real decreto 105/2008. Producción y gestión de residuos en la construcción (2008); https://www.boe.es/buscar/doc.php?id=BOE-A-20082486. (15 March 2016).

[12] Oliver, C. L., Ramírez, L. C., \& Fuertes, R. H. (2010) Una aproximación metodológica a la verificación en obra de la cuantificación de residuos de construcción en Andalucía. In SB10mad sustainable building conference, 112. Madrid.

[13] Chandrakanthi, M., Hettiaratchi, P., Prado, B., \& Ruwanpura, J. Y. (2002). Optimization of the Waste Management for Construction Projects Using Simulation. In Proceedings of the 2002 Winter Simulation Conference, 1771-1777.

[14] Yost, P. A., \& Halstead, J. M. (1996). A methodology for quantifying the volume of construction waste. Waste management \& research, 14(5), 453-461.

[15] Prairie Village, K. S. (1998). Characterization of building-related construction and demolition debris in the United States. The U.S. Environmental Protection Agency Municipal and Industrial Solid Waste Division Office of Solid Waste, Prairie Village, Kansas, 1998.

[16] Reinhart, D., Townsend, T., Heck, H., Chakrabarti, S., Cochran, K., \& Medeiros, S. (2003). Project Summary: Generation and composition of construction and demolition waste in Florida. Florida Center for Solid and Hazardous Waste Management, 123-123.

[17] Wang, J. Y., Touran, A., Christoforou, C., \& Fadlalla, H. (2004). A systems analysis tool for construction and demolition wastes management. Waste management, 24(10), 989-997.

[18] Kofoworola, O. F., \& Gheewala, S. H. (2009). Estimation of construction waste generation and management in Thailand. Waste management, 29(2), 731738 .

[19] CYPE Ingenieros, (2015); http://www.cype.es/. (4 March 2015).

[20] AEN/CTN 127. (1999). Terrazo tiles for internal use. UNE 127020:1999 EX.

[21] Cusa Ramos, J. D. (1963). Pavimentos en la construcción (No. TE278. C87 1973.).
[22] ASCER, (2006). Guía de la baldosa cerámica. Colegio territorial de arquitectos de Castellón. Werber et BroutinCEMARKSA. Valencia.

[23] WRAP. Waste \& Resources Action Programme (2009); https://www.wrap.org.uk/. (08 November 2015).

[24] Sweett, C. (2008). Reference guide NET WASTE TOOL Version 1.1. Oxford: The waste \& Resources Action Programme. Banbury.

\section{Acknowledgements}

The authors would like to express their thanks to the CONACYT for its doctoral scholarship program, to the EPSEB-UPC, the Department of Architectonic Constructions II-EPSEB-UPC, to the FIM-UAS and, finally, the Institute of Research, Support, and Innovation (INAPI) of Sinaloa, Mexico. 